\title{
MESTA Y VIDA PASTORIL
}

\author{
Fermín MARÍN BARRIGUETE \\ Universidad Complutense
}

Compuesto por cientos de ejecutorias, procesos o provisiones, el Archivo de la Mesta guarda en sus documentos otras informaciones, en apariencia fraccionadas e incoherentes, que nos permiten entrever el vivir cotidiano de los pastores trashumantes con sus costumbres y avatares. Estos hombres apegados a la tradición fueron el máximo exponente de la importancia de la ganadería en la historia castellana. Las merinadas formaban parte del paisaje, unas veces esperadas y otras odiadas, pero siempre presentes en numerosos lugares tanto de las sierras como de los extremos. El ciclo vital pastoril estaba totalmente adaptado a la naturaleza -marchas, esquileos, descansos o labores de paridera-, de ahí que resulte tan atrayente su relación, a través de la institución mesteña, con la actividad agrícola y con la evolución política en cada momento.

En general, las prácticas trashumantes se mantuvieron casi invariables a lo largo de la Edad Moderna, si bien las cuestiones coyunturales dificultaron las migraciones hasta el punto de acabar con bastantes explotaciones pecuarias. Frente a tales problemas, los pastores se resguardaban tras anacrónicos privilegios con mejor o peor suerte, mientras continuaban con los itinerarios marcados, muchas veces seculares. Por ello, el objetivo de este trabajo es una aproximación a la vida de los mesteños durante un periplo cualquiera, al margen de particularismos cronológicos y geográficos que distorsionen las situaciones.

\section{1-Condiciones de la trashumancia.}

Una cabaña estaba compuesta fundamentalmente por ganado ovino y algunas cabezas de caballar, la mayoría destinadas a la carga. También existían manadas pertenecientes al Honrado Concejo de la Mesta formadas por vacas, cerdos o yeguas, pero tenían poca importancia en comparación con las de reses lanares. El número de cabezas de la cabaña dependía de la riqueza del propietario, sin que ello alterase de forma sus- 
tancial las prácticas trshumantes. Tanto en las haciendas menores como en las mayores, la organización y trabajos precisos pasaban por la división de los animales en rebaños de unas mil cabezas, parcelados a su vez, según los casos, en hatos o grupos más reducidos, y por la elección del personal capacitado (1).

Cuando se trataba de un rico ganadero, designaba a un mayoral para que atendiese todos los asuntos de coordinación de los rebaños en las cañadas y pastos y ocupase su lugar a todos los efectos, incluso reclamaba en su nombre el cumplimiento de las leyes pastoriles (2). Persona experimentada en el arte del pastoreo, con frecuencia oriundo de tierras sorianas por su larga tradición, tenía bajo sus órdenes al resto de los pastores de cada manada: el rabadán o responsable en ausencia del mayoral, un compañero o segundo, que encabezaba el rebaño durante las marchas y también ejercía las labores más delicadas, el sobrado o tercero y el ayudador o cuarto, ambos con funciones de refuerzo, y el zagal para el cuidado de la impedimenta y de los animales de transporte. Ahora bien, esta composición no se puede considerar como un prototipo mesteño rígido, ya que las combinaciones y alteraciones dependían en gran medida de las circunstancias. Por ejemplo, en el Partido de Soria no había persona determinada delante en las marchas, alternándose el rabadán y el zagal. Además, no todos los hermanos eran grandes ganaderos, por el contrario, la mayoría de los mesteños se encuadraban en la categoría de medianos y pequeños propietarios. Ni siquiera la progresiva concentración de la riqueza pecuaria acabó con el protagonismo en el campo castellano de esos pastores, aunque el control de la Institución cayó muy pronto en manos de los más pudientes. En consecuencia, la sustitución del personal contratado por los dueños de los hatos no alteraba nada las prácticas trashumantes y el cuidado del ganado (3).

Cuando iban a las mismas zonas de herbaje, los vecinos reunían varios hatos en un solo rebaño con el fin de sortear mejor los problemas y peligros. Pero antes, herraban y señalaban cada res con marcas identificativas que permitiesen su reconocimiento y facilitasen la distribución de los impuestos y el pago de los arrendamientos. Los infractores de esta norma caían bajo penas tipificadas en los códigos mesteños, debidas a los habituales incidentes en el reparto de los mostrencos o cabezas perdidas (4). Cada pastor ocupaba su lugar para guiar al ganado, sin que en estos casos hubiera una jerarquización tan rigurosa, mas sí un escrupuloso cumplimiento de las tareas, hasta que volvían a separarse en los prados invernales o veraniegos. La tradición gregaria necesaria en una actividad tan difícil y delicada derivó, con frecuencia, en los arriendos en "compañía" de las grandes dehesas, lo que supuso el acceso a los pastos de calidad, de otro modo inalcanzables, para los menos pudientes y dio origen a una explotación comunal reglamentada (5).

Privilegios, ejecutorias o cartas insistían continuamente sobre la existencia del derecho de "posesión". Sin embargo, la carestía de los pastos durante los siglos modernos obligó a su incumplimiento hasta a los mismos hermanos del Concejo. En la medida que se limitaba el libre paso y pasto por todo el territorio, la necesidad de disponer de herbajes contratados con antelación condicionó la trashumancia y la vida pastoril. ¿Se respetaba a los anteriores rebaños y se mantenían los precios, según se ordena por la "posesión"?. No, la presión sobre los pastizales con labores, cotos y manadas estan- 
tes hizo impensable cualquier consideración cuando el propietario de las dehesas no estaba interesado. Antes de iniciar la migración, la mayoría de los ganaderos habian arrendado por anticipado las praderas, ya que no podían arriesgarse a la falta de hierba y a la consiguiente pérdida de sus reses. Aquellos que por diversas circunstancias no tomaban estas precauciones, o no podían, sufrían graves perjuicios, por lo que muchos de ellos decidían, finalmente, permanecer en las sierras y dejar las costumbres trshumantes. La normativa interna aplicada en los agostaderos e invernaderos no intimidó a los infractores, e incluso no existía seguridad de disfrute después de la adjudicación de la subasta. La letra siempre era tranquilizadora, pues el ganadero tenía derecho de amparo por los alcaldes y jueces de la Mesta, quienes le restituirían los pastos y después iniciarían el proceso, donde llevaba las de ganar (7). La realidad no se parecía en nada y los despojos terminaban por confirmarse en casi todas las ocasiones (8).

Varias yeguas y asnos acarreaban lo necesario en alimentos y útiles para las largas marchas y estancias. Los avíos eran muy variados: sal, carne, trigo, cuerdas, cuchillos, redes y ropas formaban parte de la impedimenta. El cuidado se asignaba al zagal o a otra persona que no tuviese obligaciones concretas en el rebaño, con el fin de que atendiese debidamente tanto a los animales hateros como al resto de la carga. Según las leyes mesteñas más antiguas lo imprescindible para el sustento de los pastores y sus cabañas podría comprarse donde fuera oportuno y no estaba sujeto a restricción, embargo o arancel (9). El buen aprovisionamiento para las migraciones suponía una continua tentación, de ahí que las prendas y robos menudeasen en cañadas y pastizales. Precisa para el ganado, la ingestión de sal permitía la recuperación de las ovejas después de la paridera y contribuía a la fortaleza de los animales. A razón de un quintal por rebaño, se repartía a prorrateo y, sobre todo, en los agostaderos. Exentos del tributo de la sal, los pastores la transportaban por cualquier lugar y tampoco tenían dificultades para su adquisición en las salinas (10).

Parte fundamental del rebaño, los moruecos y mansos participaban activamente en las marchas, y podían encencerrarse, en especial los segundos, para facilitar la orientación de la manada. Cuando los temporales y el mal tiempo hacían preciso la formación de un grupo compacto que paliase el frío, ayudaban a los pastores en la faena y ahorraban bastantes muertes. Los mansos, en particular, encabezaban las pastorias, y su ausencia hacía casi imposible que fueran agrupadas y hasta se perdían las últimas reses porque se desorientaban. Muy valorados por su función, los mansos como guías, en número de veinticinco, y los moruecos como sementales, en torno a cincuenta, estaba prohibido que los tomaran por prendas, penas, derechos o diezmos, y quedaban excluidos del Servicio y Montazgo (11). La elección de los mansos de entre los carneros respondía a reglas ancestrales, pues permanecían en la manada durante varios años. Antes de la castración se elegían animales "levantados, garbosos, bien hechos, de rica lana, bien encornados, sin bigote ni pelo largo", pero nunca se destinaban a tal fin los mejores machos (12).

Compañeros inseparables, los pastores y los perros recorrían las cañadas y dehesas siempre atentos a las necesidades del rebaño y a las alimañas. Durante la trashumancia vigilaban el grupo para que las reses no quedaran rezagadas, animaban el paso o cam- 
biaban su dirección. En la dehesa estaban atentos a los ataques de los depredadores y a las órdenes de reunión de las cabezas dispersas. Un código de silbidos y signos era suficiente para la comunicación y cumplimiento de los mandatos del amo, pasando el animal de la quietud absoluta a la actividad más febril. Mastines de gran porte, por lo común en número de dos por pastor, se repartían entre los atajos y rediles, de tal modo que cada uno quedaba encargado de determinadas ovejas, e incluso comía al lado del redero. Asi dispuestos, controlaban las incursiones de los lobos y zorros, contra los que luchaban sin temor. Nunca se cruzaban de forma indiscriminada y su apareamiento estaba precedido de un meticuloso estudio de los progenitores. El robo o cesión de un perro suponía una multa de cinco carneros, al igual que la posesión ilegal de los extraviados sin permiso del Concejo (13).

Desde el primero hasta el último, dueños o contratados, los pastores conocían los trabajos y exigencias de la ganadería. Como verdaderos especialistas en tales faenas, eran los responsables del éxito económico y continuidad de la explotación. Cuando se precisaba personal asalariado, la contratación siempre comportaba tensiones entre las partes, pues, por ejemplo, el celo de un rabadán o del mayoral, o la buena disposición de un ayudador incidían de forma directa sobre la rentabilidad: prevenían y curaban enfermedades, seleccionaban las crías, organizaban la paridera, repartían los pastos, etc. El ajuste anual era la costumbre, de esquileo a esquileo, si bien ésto no significaba cambios y despidos, ya que existían generaciones de pastores trabajando para el mismo propietario. La soldada variaba de unos lugares a otros $y$, normalmente, se componía de pagos en especie y en moneda. La retribución en especie tendía a desaparecer, aunque estuvo presente durante toda la Edad Moderna, a pesar de los acuerdos mesteños orientados a evitar abusos y robos ante el difícil control y los continuos enfrentamientos.

Con todo, la tradición de llevar algunas cabezas de ganado ovino y caballar pertenecientes a los pastores, "la excusa", compensaba el sueldo por la falta de gastos de apacentamiento, al incluirse con el resto de las reses (14). El arreglo implicaba numerosas obligaciones para el pastor, pues se dejaba en sus manos el rebaño. Respondía del ganado entregado y pagaba las pérdidas y los daños sufridos, bien por negligencia, bien por error; incluso si faltaban más de treinta cabezas reembolsaría la diferencia. Tampoco dejaría solo el hato o vendería alguna res, suya o no, sin justificación ante testigos. Por último, el compromiso era irrevocable y aunque tuviera más sueldo con otro amo no podía anular lo pactado (15). Las quejas sobre los salarios abundan en la documentación, siendo los amos quienes, por lo general, denunciaban la subida de los sueldos, sobre todo en el siglo XVIII, pero tampoco faltan testimonios como el siguiente:

"... y sólo la desgracia de haber nacido en un país miserable, les hace arrostrar los peligros de la trashumancia como único medio de subsistir ellos y sus familias, aunque esta se tiene que auxiliar con su trabajo hilando, pues de otro modo no podrían mantenerse con dosciento veinte reales de soldada, y la excusa de una yegua, seis ovejas y cuatro cabras" (16). 
No cabe duda que la reglamentación respondía a la denuncia de esas situaciones generales. Sin embargo, el peso de la legislación dependía por entero del acatamiento particular y la Institución poco podía hacer, salvo insistir en los mandatos. La mayoría de los pastores sólo acudían a la Mesta en caso de necesidad cuando los problemas no tenían solución por otra vía, a lo que contribuyó el dominio por los grandes señores de la maquinaria concejil, cuyos intereses no coincidían con harta frecuencia con los defendidos por los pequeños propietarios. A pesar de todo, el marco legal respaldado por el Honrado Concejo hizo perdurar las prácticas trashumantes en los siglos modernos.

\section{2- Las sierras}

Antes de la entrada en los agostaderos se procedía al esquileo. Por lo general, tenía lugar en las sierras respectivas en la segunda quincena de mayo y en el mes de junio, aunque también se esquilaban algunas cabañas leonesas en Extremadura, en especial las que pastaban en los puertos altos con el fin de que saliese más robusto el ganado. Era entonces cuando los pastores residían en sus pueblos y fijaban los contratos anuales con los amos. Mientras, los rebaños permanecían en las diferentes dependencias de los esquileos hasta concluir las tareas (17). Con anticipación, amos y mayorales acordaban el día de la llegada con los factores, que hacían acopio de alimentos y alistaban al personal adecuado. Separadas las crías, tras el ajuste de las condiciones con el capitán de tijeras y operarios, comenzaba la faena. El dueño estaba pendiente de toda la operación y, por ello, residía con su familia en el esquileo o en lugares próximos.

El inicio del ascenso suponía una actividad febril y, después de cargadas las bestias hateras, el rabadán o jefe de la manada daba la orden de marcha y animales y hombres ocupaban sus puestos. El compañero encabezaba junto con los mansos, los perros y ayudantes flanqueaban el grupo y el zagal cerraba con las yeguas. La conducción durante estos primeros días resultaba difícil y compleja porque el ganado estaba hambriento y débil. Todas las personas vigilaban para que ninguna res se apartase a pastar en las lindes de la cañada o camino, comiese demasiada hierba o ésta estuviese mojada, anduviera separada del hato con viento o lluvia helados o pasase la noche aislada. El objetivo consistía en llevar el rebaño "como cosido", a lo que contribuían los perros y el chasquido de los látigos, indispensables para animar a las reses decaídas y evitar su pérdida.

De acuerdo con un plan preconcebido que terminaba con el posible desorden y confusión, cada rebaño salía del esquileo por un cordel o vereda determinados. Sin embargo, resultaba imposible calcular el avance en estos primeros días, ni planificar los lugares donde dormir, ya que las situaciones dependían de la climatología y de los pastos disponibles. El mal tiempo aminoraba la marcha, sobre todo con temporal, por miedo a que el rebaño se "rayase" o dividiese y el ganado muriese de frío. Asi arreado, con cuidado y mucho trabajo, iba lento pero abrigado a pesar de la falta de lana, pacían en grupo y paraban a menudo para recuperar fuerzas. Los comederos improvisados en rastrojeras, barbecheras y baldíos proporcionaban la hierba, muchas veces escasa, durante los desplazamientos, pues nunca se podía prever el sitio de la parada. 
En consecuencia, hasta que las ovejas "se cubrían de tijera", morían o enfermaban bastantes cabezas por diversas causas. Cuando esto sucedía, los "sacadores" de los pueblos adquirían a buen precio todos aquellos animales incapaces de seguir la migración a los puntos de destino. En contra de las apariencias, las relaciones con los concejos y vecinos no fueron siempre distendidas en cuestiones de paso y pasto. Uno de los privilegios más antiguos de la Mesta era el libre tránsito por todo el reino, a excepción de las viñas, panes, huertos, prados de guadaña y dehesas boyales:

“... mandamos que dejen a vos, los dichos pastores e a vuestros ganados mayores y menores de dicha nuestra Cabaña ir y pasar por todas las partes y lugares y términos de los dichos nuestros reinos y señoríos, asi realengos, como abadengos y señoríos... paciendo las hierbas y bebiendo las aguas... “ (18).

Pero perseguía una utopía, pues a lo largo de la Edad Moderna la antigüedad de la concesión se contrarrestó con una feroz oposición, en nada mediatizada por las esporádicas intervenciones de los jueces cabañiles. Es más, desde mediados del siglo XVI, aparecieron nuevas imposiciones destinadas a evitar el paso y pasto de los ganados por los términos municipales, destacando la pena de "los doce maravedíes de día y de los veinticuatro maravedíes de noche" (19). Así las cosas, con suerte contaban con las vías pecuarias abiertas y algunas zonas pasteñas permitidas por las ordenanzas locales.

Una vez en los puertos, tras la operación de salar el ganado, el rabadán o el dueño inspeccionaba los prados con el objeto de eludir los sitios donde abundaban hierbas venenosas o indigestas, doblemente dañinas con rocio, por lo que los hatos se soltaban tarde. Los inconvenientes de la trashumancia- escasez de hierba, aguas estancadas, frío, cansancio, etc.- favorecían la aparición de determinadas enfermedades, como la sarna o la viruela. En tales casos, existía la obligación de apartar las reses infectadas o poner en cuarentena todo el rebaño en un terreno aislado destinado a los "ganados dolientes".

Desde la majada salían cada día a los pastos más o menos cercanos, unos de libre aprovechamiento, los menos, y otros arrendados, en numerosas ocasiones disponibles hacía poco tiempo. El habitat disperso de las sierras posibilitaba la residencia de los pastores en sus pueblos o en lugares vecinos, de ahí que el aprisco se situase en las cercanías y los chozos sólo sirviesen como refugio de los encargados de la guardia. La división en hatos se debía a cuestiones de maniobrabilidad, salvo que la manada estuviera compuesta por cabezas de varios propietarios que separasen las suyas. Faltaba aquí el meticuloso estudio de los apartados en espera de la paridera de la invernada y, únicamente, se procedía a la selección en años de escasez de hierbas. Cuando era posible, los moruecos permanecían apartados hasta que las crías se destetaban por completo y las madres recuperaban el vigor de cara a un nuevo apareamiento, pues, de otro modo, se necesitaba empetar a los sementales para impedir la reproducción indiscriminada y a destiempo, que conllevaba nacimientos prematuros en las cañadas sin las debidas atenciones.

Personajes siempre ignorados y de gran importancia en las prácticas trashumantes, 
el alcalde de cuadrilla significaba la salvaguarda de las leyes de la Mesta principalmente en las sierras, aunque también quiso hacerse extensivo a los invernaderos sin apenas éxito. Cada cuadrilla nombraba a sus alcaldes por cuatro años entre aquellos que poseían quinientas ovejas o cabras o sesenta vacas o yeguas. Tenía competencia en todo lo relativo a la Cabaña Real, ya fuese en las diferencias entre hermanos o en los problemas referentes a su entorno agrario. Robos, prendas, venta de hierbas, disfrute de prados, tasación de daños y repato de mostrentos, eran algunos de los puntos de su jurisdicción según las atribuciones otorgadas en los códigos (20). Pero tanto la oposición de los propios mesteños, que se negaban a la fiscalización de la actividad pecuaria, como de los concejos y particulares, acabó por reducir sus intervenciones a los tres casos conocidos: señalamiento de tierra a los ganados enfermos, convocatoria de mestas y despojos de "posesiones". Las condiciones de Cortes de la primera mitad del Seiscientos terminaron por circunscribir, definitivamente, sus actuaciones a dichos asuntos, además de restarles credibilidad por las agudas críticas y favorecer el incumplimiento de los mandatos (21). Estos alcaldes, por la vinculación con el Honrado Concejo, representaban el nexo entre la Institución y los ganaderos, si bien nunca tuvieron el papel designado en la legislación, y a finales del siglo XVIII se habían convertido en un cargo anacrónico e ineficaz, muestra evidente de la decadencia de la trashumancia (22).

A pesar de todo, los pastores mantuvieron en las sierras bastante relación con los alcaldes de cuadrilla debido al papel de directores de las mestas locales y, aunque no fuesen demasiado efectivas sus órdenes, a la participación en los problemas cotidianos, por ejemplo, en la adjudicación de las reses perdidas o en la distribución de los pastos comunales; es decir, influían en la articulación de la vida pastoril durante el verano. Curiosamente, los mesteños consideraron los agostaderos como su medio particular al hallarse en tierras conocidas y descuidaron el cumplimiento y aplicación del aparato jurídico de la Organización. Mucho más autónomos en sus comportamientos aquí que en las cañadas e invernaderos, no potenciaron el cargo de alcalde de cuadrilla fuera de las reuniones pecuarias y no supieron utilizarlo en el capítulo de hierbas. Pensaron que la carestía nunca alcanzaría a las sierras, cuando, en realidad, casi es un fenómeno simultáneo y con infinidad de ramificaciones: roturaciones, vedamientos, alteración de las subastas de pastos, reventas, rechazo de concejos y particulares, incumplimiento de leyes, etc.

Muy pronto, a finales del siglo XV, las denuncias de labores en tierras pasteñas, de pequeña extensión y en los mejores sitios, abrió el episodio de las roturaciones en las montañas; así, los casos de San Pascual (Avila) y de Agreda (Soria) fueron meros exponentes de una situación que se perpetuó hasta la desaparición del Honrado Concejo, fenómeno imparable incluso para la "poderosa" legislación (23). En numerosas ocasiones, el cultivo estuvo precedido de la concesión de licencias con algún motivo determinado, que, además, entorpecían las sentencias de los alcaldes entregadores porque no conocían su duración y concejos y particulares pretendían la perduración del aprovechamiento. Tales permisos cerraban superficies considerables, a veces de hasta 1000 fanegas de sembradura, con carácter casi irreversible por la falta de control oficial y el 
respaldo de la costumbre en la dedicación, cuya consecuencia inmediata era el desvío de los caminos pecuarios hacia otras zonas pasteñas (24). Los jueces cañadiegos sentenciaban los cultivos en pastizales, pero las numerosas infracciones denunciaban la escasez de tribunales y magistrados y la ausencia de mecanismos adecuados. Las Cortes de Valladolid de 1548 fueron el marco de airadas disputas cuando los procuradores reclamaron soluciones a la falta de pastos por la siembra indiscriminada de comunales y concejiles (25). Los testimonios sobre usurpaciones solían terminar con la misma frase, incluso en el siglo XVIII, “... la mayor parte de ello les había sido mandado dejar por los otros alcaldes entregadores y no lo habían querido dejar..."; síntoma de las frecuentes reincidencias, de la inobservancia de las disposiciones legales, de los problemas ocasionados con la venta de baldíos por la Real Hacienda y con el "Servicio de los Ocho Millones de Ducados" de 1591 y, por último, de la impotencia de los agentes del Concejo en las chancillerías (26).

Desde los memoriales de 1619, 1627 y 1649, que achacaban la disminución de los ganados a la estrechez de los pastos debida a las roturaciones de herbajes, donde el Honrado Concejo de la Mesta mantenía una actitud beligerante, hasta las relaciones de alcaldes entregadores del Setecientos, con evidencias de la decadencia de la Institución, las dificultades encontradas por los pastores en las sierras fueron tan importantes, y no sólo en el capítulo de rompimientos, que hacia 1780 la mayoría de los pequeños propietarios habían abandonado las prácticas trashumantes. En esta centuria, los precios de la lana enriquecieron aún más a los grandes ganaderos, acaparando el mercado de pastos, bastantes de ellos, paradójicamente, residentes en "tierras llanas" (27).

Agresiones, acotamientos y exacciones tuvieron los mismos efectos, al tiempo que suponían la demostración palpable del rechazo a las prerrogativas otorgadas a la Mesta. Aunque no pocas de las nuevas dehesas aparecieron como consecuencia de licencias y provisiones, otros cotos surgieron por la decidida oposición de concejos y particulares y los altos precios de los pastos. Sin la entrada de los rebaños, los alcaldes entregadores y otros delegados no tenían jurisdicción y la autonomía municipal en materia ganadera quedaba asegurada, sobre todo cuando defendían las ordenanzas locales y los intereses de los estantes. Tampoco sirvieron de nada las leyes que amparaban la trashumancia, la confirmación de los privilegios cabañiles y la política procesal de la Organización, pues los ediles no atendían las demandas de los ganaderos, e incluso participaban en los delitos, la Corona no mostraba un apoyo decidido y la Mesta carecía de la fuerza suficiente para frenar la actitud contraria del mundo agrario. Muy frecuentes eran las "prendas" tomadas a pastores y rebaños, consistentes en un número variable de cabezas, cuchillos, lana, trigo, capas, etc., como respuesta inmediata al descontento por el tránsito de las reses foráneas, sin que las sentencias de restitución de los magistrados mesteños redujesen el número de casos. El resentimiento derivaba del libre aprovechamiento de las hierbas y de la escasez padecida a lo largo de la Edad Moderna por los hatos vecinales. Ejemplo significativo fue el arriendo de los términos públicos y concejiles por los vecinos de la villa de Agreda (Soria), en 1561, porque los serranos no les dejaban apenas pastos, siendo inútil la multa impuesta para su abandono(29). 
Hacia 1640, la coyuntura favorable a la contestación de las prerrogativas ganaderas provocó la reactivación de los vedamientos, agresiones, infracciones, y a finales de la centuria los alcaldes entregadores no se atrevían a establecer sus audiencias fuera de los itinerarios habituales ante la feroz oposición y la negativa de los pueblos a acudir a sus llamamientos. Esta postura preludió el miedo latente perceptible en las averiguaciones de las denuncias durante el Setecientos y las risibles multas aplicadas a los culpables. Los abusos llegaron a tales extremos que se extendieron las denominadas "penas de cercanía", es decir, el rebaño más cercano al daño descubierto en los cotos pagaba su importe sin ningún tipo de averiguación preliminar. Ni que decir tiene que, en la mayoría de las ocasiones, las denuncias eran inventadas por los guardas y oficiales municipales, empeñados en disuadir a los pastores de atravesar sus términos(30).

¿Qué solución quedaba? Unicamente, el arriendo de las hierbas, la avenencia con los pueblos, la aceptación de condiciones de todo tipo, el rechazo de las leyes de la Mesta y el respeto a las ordenanzas locales. El derecho de "posesión" en las sierras estaba regulado al igual que en los invernaderos, pero si allí no surtió efecto, en los agostaderos apenas se esgrimió por el temor a la pérdida de los herbajes y al alza desmedida de los precios. Siempre necesitados de dinero, los ayuntamientos acotaban los prados para su posterior venta, y no faltaron ejemplos de acaparamientos destinados a las lucrativas reventas alentadas por la carestía y la compra a cualquier precio. Rastrojeras y barbecheras tampoco estuvieron al margen del fenómeno y, cuando la demanda lo hacía aconsejable, se vendían al mejor postor ante la impotente mirada de los demás ganaderos, temerosos de esgrimir los privilegios del Concejo por las posibles represalias. Como resulta lógico, en aquellas zonas donde disminuía la presión, los conflictos eran menos virulentos y la vida pastoril transcurría sin apenas incidentes, salvo los debidos a las ordenanzas locales en materia de paso y pasto.

Condiciones climatológicas y geográficas favorecieron la existencia de lugares de apacentamiento de fácil acceso para los hatos serranos, aunque no por ello los pastores estaban en posición de enfrentarse con los dueños de los prados, a pesar de disponer de un abanico de posibilidades. Tal actitud conciliadora se desprende de las pocas denuncias de despojos de arriendos de agostaderos expuestas en las juntas generales. Además, los mismos hermanos consideraban que la "posesión" se aplicaba en todo caso en los invernaderos y de forma excepcional en los agostaderos, dejándoles libres para concertar los contratos y pujar en las subastas sin incurrir en delito frente al Honrado Concejo de la Mesta(31).

Durante el verano, los animales recuperaban la lana y habían engordado con los pastos de las alturas, y los pastores no habían tenido otro trabajo con el ganado que el de la vigilancia habitual y la última selección de ovejas parideras, borregas de recrío y carneros jóvenes de cara a la reproducción. La unión de los hatos de moruecos con el resto del rebaño iba precedido de una especie de ceremonia ritual, compuesta por sonidos y gestos, destinada a evitar la muerte de los sementales por golpes en las peleas nupciales, agotamiento por cortejo y cópulas o fracturas por carreras y agolpamientos. Los machos se distribuían por igual entre toda la manada, bajo la atenta mirada de los pastores, con el objeto de separar a los que daban muestra de excesiva fatiga y repetir 
la operación en días sucesivos hasta el acoplamiento definitivo de las reses. Cuando los moruecos pastaban mezclados con las hembras en los grupos pequeños de un solo dueño, y se les quitaba el peto, había que seguir las mismas reglas y proceder a su aislamiento durante parte del día. Sólo aquellas borregas demasiado jóvenes formaban un hatajo aparte desde antes de las faenas reproductoras.

\section{3.- Cañada abajo}

Entre finales de agosto y mediados de septiembre, después del apareamiento, se emprendía la marcha hacia las praderas templadas de los extremos. Si el otoño se presentaba bueno y septiembre traía agua, la hierba verde nacía en cualquier sitio y ponía en peligro al ganado por las diarreas y aparición del "sanguinuelo", también presente en polvo abundante. No obstante, la humedad era preferible porque otoñaba la tierra con pasto para todo el invierno y contribuía a la mejora de las prácticas trashumantes.

Como en otras ocasiones, la hora de la partida suponía una actividad febril por la preparación de los avíos, el señalamiento del ganado y las últimas visitas de los pastores a sus casas. El día de la marcha estaba previsto de antemano, dependiendo de la terminación de los contratos de arriendo, del mal tiempo en las sierras, la falta de pasto o lo avanzado de la estación. Con año seco la costumbre aconsejaba adelantar la salida, aunque, por lo general, sucedía lo contrario, con el fin de aprovechar al máximo la hierba disponible en lo alto y encontrar cuajadas las dehesas de invernada; además, la falta de abrevaderos provocaba con frecuencia desvíos obligados y los consiguientes retrasos. Los sorianos defendían la regla del "ganado con polvo en la dehesa" con el argumento de que preferían desollar quietos a encontrarse en la cañada y, así, reducían las pérdidas. En tal momento, todos los pastores debían estar presentes y a la orden del mayoral o encargado del rebaño se iniciaba la migración en el orden ya comentado y por las vías pecuarias elegidas según el destino final.

Rabadán y compañero, o aquellos encargados de sus mismas funciones, tomaban la dirección de la manada, pues a la salida de las montañas se encontraban zonas con hierba demasiado verde, rastrojeras, barbecheras y plantíos, donde los vecinos querían que pernoctasen los animales para que limpiaran y abonaran los campos. Pero esto era muy peligroso, porque el ganado podía embasquillarse o atracarse y se necesitaba mucho esfuerzo y cuidado en su distribución, al igual que para evitar la ingestión en exceso y la aproximación a los abrevaderos corrompidos. Los mansos jugaban en estas faenas un papel de primer orden y, rápidamente, desviaban el rebaño tras la señal del pastor, por tanto era preferible que sobrasen o suplirlos con machos cabríos encencerados, llamados "guías"(32).

Un ritmo de marcha más que aceptable significaba de cuatro a seis leguas, veinte o treinta kilómetros, y un mes atravesando cañadas, caminos y pastos hasta completar los quinientos kilómetros, aproximadamente, que separaban ambos extremos. Dicho así, parecía un recorrido fácil y rutinario por su frecuencia semestral, pero este planteamiento distaba mucho de la realidad. Los pastores, fuera de sus lugares de residencia, 
estaban a merced de las circunstancias y, si en las sierras los problemas no faltaban, en las cañadas e invernaderos las dificultades rompían cualquier pensamiento idílico. Las descripciones hablaban de abastecimientos en el camino, pero ignoraban el rechazo por las exenciones de impuestos, comentaban los arbitrios locales, pero ocultaban los excesivos cánones y prendas, denunciaban los privilegios de paso, pero callaban las agresiones y cotos.

En estos asuntos de vital importancia, la Mesta no descuidó su aparato legal, formado no sólo por privilegios, sino también por ejecutorias, provisiones, reales cédulas, autos y cartas, procedentes de intervenciones particulares de la Institución durante los siglos modernos. Ordenaba la anchura y estado de las cañadas y las multas por usurpación, analizaba las imposiciones legales, acusaba a pueblos y vecinos de agresiones, etc., si bien no contaba con los medios adecuados a su alcance ni con el respaldo real. En teoría, cualquier eventualidad estaba prevista, por ejemplo, cuando había desbordamientos de los ríos y el paso quedaba cortado, dos personas nombradas por ambas partes señalaban pastos a los rebaños detenidos y tasaban el precio de las hierbas hasta la salida. En la práctica, los pastores apremidados por los sucesos aceptaban las condiciones establecidas por los dueños de las dehesas, con el fin de evitar la muerte de los animales(33).

Las esporádicas visitas de los alcaldes entregadores no disuadieron a los concejos y vecinos del cierre u ocupación, e incluso cambiaron los trazados de las cañadas por zonas menos fértiles, y provocaron pleitos y agravios a los ganaderos desorientados. Las penas eran mínimas y, en muchas ocasiones, se limitaban a la apertura de los caminos y al restablecimiento de los mojones originarios, sin ninguna medida adicional. Tras la aceptación de los derechos de tránsito por los pueblos, el siguiente paso consistía en obstaculizar e impedir la salida de los rebaños de los itinerarios fijados. Problema muy grave, porque, únicamente, los agrimensores ponían lindes en las cañadas reconocidas entre las "cinco cosas vedadas" y el resto, en conjunto, tenía la denominación de "cañada abierta". Estas situaciones aumentaron la oposición de pueblos y particulares, que contemplaban como los delegados del Concejo no limitaban las mediciones para facilitar la trashumancia de las manadas.

A mediados del Quinientos una de las mayores preocupaciones de la Mesta se centraba en el control de las cañadas y pasos, animada por el aparente apoyo de la monarquía, e hizo extensivos los amojonamientos a majadas, abrevaderos, veredas y coladas. Los sitios cultivados o cerrados volvían a abrirse al paso de los rebaños, que pastaban "lo nacido" sin que pudieran quejarse los labradores. Después de varias sentencias en reincidencia las multas se doblaban y, por último, cuando los infractores persistían en sus propósitos, se les encarcelaba. Este tono amenazador duró muy poco, ya que a finales de la centuria los problemas de la Real Hacienda acabaron, definitivamente, con el respaldo real, y las reivindicaciones del Honrado Concejo se convirtieron en inadmisibles por la respuesta del campo. Hacia 1680, las audiencias de los alcaldes entregadores estaban localizadas en las zonas menos conflictivas y la medición de lạs cañadas y caminos cayó en un ritual que demostraba la condescendencia de los ayuntamientos con los oficiales mesteños. El siglo XVIII presenció con estupor la existencia de au- 
diencias fijas y rotativas, donde apenas una veintena de pueblos aceptaban la fiscalización de los magistrados cabañiles, quedando el resto sin ninguna comprobación. No tuvo nada de estraño que los ganaderos se quejasen en las juntas generales del cierre de las principales arterias de la trashumancia y de la desaparición de las "cañadas abiertas" no amojonadas, pues los libros de apeos consistían en papeles rellenos de antemano y con espacios en blanco para ser completados con cada caso. ¿Qué había pasado con la Institución cuya jurisdicción llegaba hasta donde concluían las vías pecuarias y se cumplían sus privilegios de paso y pasto? (34)

Además de los impuestos habituales y medievales, como el Servicio y Montazgo en los puertos reales, el derecho de castillería o el de asadura, los mesteños hicieron frente al aumento de las exigencias en los arbitrios tradicionales y a la creación de otros nuevos, todo ello unido a la proliferación de malos tratos, robos y acotamientos. Los concejos mostraron un deliberado interés por agraviar a los rebaños, con el objetivo de disuadirlos de pasar y pastar en sus términos y, así, eludir para siempre las prerrogativas cabañiles (35). Las provisiones promulgadas contra las justicias, encargadas de la vigilancia de los privilegios de la Mesta y de las restituciones de lo tomado, se diluyeron entre los enfrentamientos por la defensa de la autonomía municipal (36). Las causas por penas, prendas, pontazgos, portazgos, "penas de cercanía", borras, "los doce y los veinticuatro maravedíes", etc., plagaron las cañadas y vías pecuarias y sirvieron para los propósitos de los autores e instigadores. El examen, en 1758, de los arbitrios locales con vistas a la eliminación de los ilegales y excesivos, confirmó que

“...eran tantos los derechos impuestos a los ganados en sus tránsitos, que no hollaban suelo sin adeudo, entre los cuales el más injusto, ya que no en su origen, era el que nombraban castillería..."

Pero Campomanes pronto acabó con todas las iniciativas favorables a la Institución. Por Real Orden de 1780, la recaudación de los derechos de peaje, pontazgo, portazgo o castillería, se destinaba al mantenimiento de caminos y vías de comunicación, es decir, legalizaba las exacciones tal y como estaban evaluadas en ese momento despojaba a la Mesta de la posibilidad de recurso en temas de su competencia (37).

\section{4.- Los extremos}

A la entrada en los invernaderos precedía la inspección de las dehesas arrendadas con anterioridad. A pesar de los privilegios de pasto, ya a mediados del siglo XVI casi ningún ganadero bajaba de las montañas sin los prados apalabrados o sin la promesa de acopio en los sobrantes de los grandes arrendamientos, ya que de otro modo estaba obligado a la compra de herbajes caros y de poca calidad de los baldíos o en lugares montuosos. Los pueblos y particulares aceptaban de mala gana el paso accidental de las merinadas por sus tierras, pero nunca permitían la permanencia en sus pastizales, incluso rastrojeras, pampaneras o barbechos, destinados a la venta. Tras las oportunas averiguaciones, el mayoral distribuía los rebaños por las dehesas o los pequeños propietarios mancomunados se dirigían a los herbajes. 
Cada uno en su destino, iniciaban las tareas más apremiantes: la descarga de las bestias hateras, con la última comprobación de si se disponía de lo preciso en víveres, ropas, herramientas o redes, el apuntalamiento de los chozos y el reparto de las reses. Dividido el rebaño en grupos de diverso tamaño, normalmente seis rediles hasta principios de febrero y después cinco hasta la salida para las sierras, los rabadanes o los dueños, mientras llegaba la paridera, reparaban el chozo grande, destinado a la cena y reunión de los pastores y a vivienda del rabadán y del zagal, y construían los chozuelos, según el número de hatajos, al lado de las majadas. Aquellos ganaderos sin "posesión" levantaban los refugios nuevos todas las temporadas y trabajaban mucho en la asignación de los hatos porque no conocían el terreno y precisaban informarse antes sobre las diversas calidades de la hierba y accidentes geográficos. Para evitar problemas, era aconsejable utilizar una red nueva y aprovisionarse de estacas suficientes en los corrales y estaquillas con "atiles" para las madres y el cordero. En campo abierto y en zonas llanas no debían faltar los leñeros destinados a la fabricación de las compuertas de escoba que salvasen de la ventisca a los animales, en especial a las crías. Aunque los privilegios son tajantes en este sentido, bastantes pleitos sobre prendas y agresiones se originaron por la tala en los bosques y montes (38). Por último, los pastores recorrían la dehesa para apartar o degollar las reses enfermas o muy débiles, aunque se tratase de enfermedades poco relevantes, como la sarna.

Sin embargo, los trabajos anteriores carecían de importancia ante la inminencia de la paridera. El rabadán o el dueño observaban continuamente a las preñadas y, llegado el momento del parto, sabían cuál podía con la cría y la que necesitaba compañera, es decir, la gorda con la flaca. Las labores de ahijeo eran las más difíciles, y aquí el pastor demostraba su eficacia y conocimientos, por ejemplo, el redil de las preñadas se colocaba en sitio llano para que el cordeno no rodase al nacer, las crías únicas debían amamantarse con las madres, la que no quería se ataba, cada oveja tendría su cordero y degollaban en el acto los borregos de mala calidad y colocaban la piel, empellejaban, a los buenos de la reserva por abandono de la madre o por pérdida. El fin último consistía en el cuidado de la finura de la lana, de ahí la importancia de la selección, y sólo cuando morían muchas crías se sustituían por malas, en especial machos porque duraban poco en el rebaño. Ayudado el rabadán por el compañero en la paridera, el resto del equipo quedaba a cargo de las preñadas. Concluido el ahijeo, se volvía a distribuir la manada para aliviar las partes de la dehesa agotadas durante la paridera. Las ovejas nunca estaban solas, ni siquiera de noche, ya que las alimañas de todo tipo acechaban los hatos y hombres y perros vigilaban los pastizales y corrales.

El invierno pasaba en estas ocupaciones. Pero en marzo, de nuevo, comenzaban los preparativos de "cañada arriba" hasta el esquileo: el raboteo de los borregos, la elección de moruecos y mansos, el sacrificio de sementales y ovejas viejos, la corta de los cuernos y la venta del sobrante seleccionado a otros ganaderos para que mudaran la sangre. Los animales comían cuanto querían y los pastores estaban bastante descuidados, aunque alertas por si aparecían enfermedades como la "cucharilla" y la "amarilla", ambas con inflamación de hígado, debidas a los cambios de estación, la escasez de hierba, majadas húmedas y rediles estrechos. 
Tampoco la vida en las dehesas carecía de las dificultades y problemas tratados en las sierras y cañadas, es más, tenían mayor gravedad. No cabe duda de que los amplios pastizales de los extremos sufrieron un impulso roturador desmedido y miles de fanegas de herbajales se convirtieron en tierras labrantías, al igual que los propios y comunales. Los rompimientos se produjeron sobre todo en las dehesas concejiles, debido a los usuales repartos entre los vecinos. Licencias y facultades protegieron las incursiones del arado y posibilitaron las perduración de los cultivos fuera de su periodo de vigencia (39). Las prendas, penas e imposiciones, nuevas o tradicionales, fueron los mecanismos utilizados en la defensa de los intereses locales, pues los guardias visitaban los pastizales con sus exigencias con el pretexto de ordenamientos municipales y daños en los cotos. Los alcaldes entregadores nada pudieron frente a la arrogancia de concejos y particulares y sus sentencias derivaban, finalmente, en ánimos encrespados contra los privilegios de la Institución. Por ejemplo, los sucesos portugueses de 1640 provocaron la ausencia de visitas durante décadas en amplias zonas cercanas a la frontera, que terminaron por inhibirse de la jurisdicción de la Mesta y de sus magistrados (40).

Otra vez el tema de la carestía de hierbas se situaba en el centro de la controversia. La reducción de la superficie pasteña y los acotamientos indiscriminados causaron la falta de pastos y el trastocamiento de la vida pastoril en los invernaderos. La "posesión" pasó de suponer una ilusión de los ganaderos a un arma arrojadiza contra la Organización, resultando tan ineficaz como siempre, a no ser que los dueños de los herbajes tuvieran interés directo en la continuidad de los mismos arrendatarios. Por su lado, las interferencias de los riberiegos no hicieron más que enturbiar la situación y agudizaron las tensiones por el disfrute de los arrendamientos, en teoría monopolio de los serranos (41). Los altos precios, las conflictivas subastas y pujas, las abundantes reventas fruto de la especulación, el incumplimiento de la tasa o las Pragmáticas de 1633 y 1680 , encubrieron los agobios de la mayoría de los pequeños y medianos ganaderos para disponer de pastos suficientes, aunque fuese de pasturajes secundarios. Mientras que los grandes señores acaparaban las mejores dehesas, el resto luchaba por zonas que hacian poco tiempo eran de libre aprovechamiento, fenómeno agudizado en el siglo XVIII por la rentabilidad de las explotaciones pecuarias, consecuencia de la especial coyuntura del mercado lanero.

Perdido el primitivo espíritu democrático de los pastores y rota la vinculación de la ganadería trahumante con el entorno agrario, la Mesta no supo o no pudo conservar la pureza de la vida pastoril. Contaminada por cuestiones políticas, económicas y sociales, era casi un recuerdo a finales del Setecientos.

\section{NOTAS}

(1) Estos aspectos han sido abordados, entre otros, por KLEIN, J.:La Mesta, 1981, pags. 31 y ss, DEL RIO,M.: Vida pastorial, Madrid, 1828, reed. Madrid, Ediciones el Museo Universal, 1986 
y GARCIA SANZ,A.: "Negocio lanero y vida pastorial", en Historia 16, (1984), n. 93, pags. 6071 .

(2) Cuaderno de Leyes de Mesta de 1731, segunda parte, titulo XXXIII, ley VII, pág. 225.

(3) RUIZ MARTIN,F.: "Pastos y ganaderos en Castilla: La Mesta (1450-1600)," en Actas de la Primera Semana de Estudios de Prato de abril de 1969, Florencia 1972, pags. 271 a 285. MARIN BARRIGUETE,F.: "Campomanes, Presidente de la Mesta", en Actas del Coloquio Internacional sobre Carlos III y su Siglo, tomo II, Madrid 1990, pags. 93 a 115.

(4) Cuaderno de Leyes de Mesta de 1731, segunda parte, titulo XXXIX, ley I, pág. 244.

(5) Ibidem, titulo VI, ley X, pág. 80. Textualmente dice: "Si algún hermano por si o por su procurador, arrendare para sus ganados alguna dehesa de compañia, tenga la posesión de ella segun el ganado que en ella pusiere el año primero... Y si alguno se quisiere ir con su ganado de la dicha dehesa no pueden dar su posesión a otro, y quede para dicha compañía".

(6) Acuerdos del Honrado Concejo de la Mesta, libros 518 y 519. Aquí se recogen numerosos informes que denuncian tales situaciones.

(7) MARIN BARRIGUETE, F. La Mesta en los siglos XVI y XVII: roturaciones de pastos, cañadas, arrendamientos e impedimentos de paso, tomo I, Madrid, 1987, pag. 396.

(8) Acuerdos del Honrado Concejo de la Mesta, libros 500 a 520. En los apartados correspondientes a despojos y amparos de "posesiones".

(9) Cuaderno de Leyes de Mesta de 1731 , primera parte, privilegio XIX, pág. 41; privilegio XXIII, capítulo II y III, pág. 55 y capítulo IV, pág. 57; privilegio XXV, pág. 61.

(10) Ibidem, privilegio XXX, pág. 99.

(11) Ibidem, privilegio V, pág. 16. Segunda parte, título XXXIII, ley IV, pág. 224.

(12) DEL RIO, M. Op. cit. pag 139 y ss. Este ganadero insiste en que: "La elección de los mansos requiere igual esmero que la de los moruecos; aquellos se conservan hasta que ya son viejos y no sirven y no es necesario que sean tan finos como estos... cuando un ovejero tiene un manso sobresaliente, lo conserva tanto que da lugar a que se muera...".

(13) Cuaderno de Leyes de Mesta de 1731, segunda parte, titulo XXXII, ley VI, pág. 222.

(14) Acuerdos del Honrado Concejo de la Mesta, libro 501. En Junta de 12 de septiembre de 1517 se estipuló que:"...por los inconvenientes que se ven en dar las soldadas que se dan a los mozos, que ninguno sea osado de dar a mozo ninguno, ni a otra persona que le haya de servir, si no a dinero, poco o mucho, lo que se igualaren, y no en otra ninguna...".

(15) Cuaderno de Leyes de Mesta de 1731, segunda parte, título XXXII, ley VII, pág. 222 y ley IX, pág. 223; titulo XXXVII, ley I y II, pág. 230, ley V, pág. 231 y ley VI, pág. 232.

(16) DEL RIO M. Op. cit. pág. 153

(17) Se dividían en "rancho" o estancia para esquilar, "bache" o sudadero, lonjas o almacenes, "pequera" o lugar para calentar la pez con que señalar las reses esquiladas, "refertorio" o comedor y dormitorio. GARCIA SANZ, A. Op. cit. pág. 69.

(18) Cuaderno de Leyes de Mesta de 1731, primera parte, privilegio LVI, folio 167.

(19) Un ejemplo al azar es el de la villa de Madrigal del Monte (Burgos), en 1550, Ejecutorias y Sentencias, A.H.N., A.Mesta, leg. 119, exp. 10. Otros muchos casos se encuentran en Sentencias de los Alcaldes Entregadores, libros 325-326.

(20) Cuaderno de Leyes de Mesta de 1731, segunda parte, titulo V, pág. 58 y ss.

(21) Ordenanzas y Privilegios, A.H.N., A. de Mesta, leg 242, exp. 63. A.G.S. Patronato Real, $\operatorname{leg} 89$, folio 336 y ss.

(22) MARIN BARRIGUETE, F. "Campomanes...", pag. 106.

(23) Ejecutorias y Sentencias, leg 99, exp. 18. Abecedario de provisiones para romper dehesas, libro 263, pags. 102 y 119; libro 267, pag. 140. Ordenanzas y Privilegios, leg. 240, exp. 61. 
En 1525, Carlos I decretó que todos los pastos roturados antes de los ocho primeros años de su reinado volvieran a su primitivo estado, poniendose a disposición de los ganaderos, KLEIN J, $O p$. cit. pág. 334.

(24) La villa de Laguna de Cameros (Logroño) consiguió en 1530 la renovación, por otros diez años, de la licencia para roturar más de 900 fanegas de sembradura en su dehesa, Abecedario de Provisiones... Libro 263, pag. 171 y ss.

(25) Ordenanzas y Privilegios, leg. 241, exp. 45.

(26) MARIN BARRIGUETE, F. La Mesta en los siglos XVI y XVII...; todas estas cuestiones se tratan en los capítulos correspondientes de manera muy amplia. VASSBERG D.E., La venta de tierras baldias. El comunitarismo agrario y la Corona de Castilla en el siglo XVI, Madrid 1983. GARCIA SANZ, A. "Bienes y usos comunales y el proceso privatizador en Castilla durante los siglos XVI y XVII: el caso de tierras de Segovia”, Hispania, XI, 144 (1980), pp. 95-126.

(27) Memorial del Rey D. Felipe III sobre la conservación del noble Concejo de la Mesta, B.N. ms. 2.350, folio 250 y ss. Mermorial de D. Antonio del Río, A.H.N., Consejos, leg. 7.133. Memorial de las principales causas que han provocado la disminución de los ganados, Ordenanzas y Privilegios, leg 245, exp. 15. Relaciones de Alcaldes Entregadores, A.H.N. A. de Mesta, libros 461-4, 468-74, 483-8, 495-9. GARCIA SANZ, A. "La agonia de la Mesta y el hundimiento de las exportaciones laneras: un capítulo de la crisis económica del Antiguo Régimen en España", en Agricultura y Sociedad, 6 (1978). SANCHEZ SALAZAR, F. Extensión de cultivos en España durante el siglo XVIII, Madrid, 1986.

(28) Provisión de 1554 contra el aumento de las penas y agresiones y el incumplimiento de los privilegios del Honrado Concejo de la Mesta, Ordenanzas y Privilegios, leg. 241, exp. 49.

(29) Ejecutorias y Sentencias, leg. 2, exp. 4.

(30) Por ejemplo, en 1610 el Concejo de EI Moral (Segovia) fue sentenciado por multar a los ganados mesteños con "penas de cercanía", Ejecutorias y sentencias, leg 134, exp. 12.

(31) Cuaderno de Leyes de Mesta de 1731, segunda parte, título VI y su anexo. Acuerdos del Honrado Concejo de la Mesta, libros 500 a 520.

(32) DEL RIO, M. Op. cit., pág. 36 y ss.

(33) Cuaderno de Leyes de Mesta de 1731, primera parte, privilegio VI, pág. 19, privilegio XL, pág. 128, privilegio LIX, pág. 195. Segunda parte, titulo XL, pág. 245, título XLII, pág. 246, título XLVII, pág. 251. BRIEVA, M. Colección de leyes, reales decretos y órdenes, acuerdos y circulares pertenecientes al ramo de la Mesta, Madrid, 1828.

(34) Apeos y visitas de cañadas, A.H.N., A. de Mesta, libros 355 a 435.

(35) Por ejemplo, en 1525 se condenó al Concejo de Salmerón (Guadalajara) porque había exigido en sus cotos más cantidad de la apreciada por los jueces, Ejecutorias y Sentencias, leg. 178, exp. 7. MARIN BARRIGUETE, F. La Mesta en los siglos XVI y XVII...

(36) Cuaderno de leyes de Mesta de 1731 primera parte, privilegio XXXIX, capítulo XV, pág. 127, y privilegio LIII, pág. 148 y ss.

(37) BRIEVA, M. Op. cit. págs. 132 y ss., 203 y 204.

(38) Cuaderno de Leyes de Mesta de 1731 primera parte, privilegio XXIII, pág. 54. Dice: "E otrosi, que corten leña verde y seca para cocer su pan y su carne, la que hubieren menester, e que corten madera para hacer puentes en los rios, por donde pasen sus ganados y sus hatos, y todas las cosas que hubieren menester".

(39) La villa de Andújar (Jaén) pudo labrar 300 fanegas de sus concejiles por seis años en 1591. Abecedario de provisiones para romper dehesas, libro 268, pág. 45.

(40) Acuerdos del Honrado Concejo de la Mesta, libro 508, folio 62 y ss.

(41) Concordia de 1556 entre los mesteños y los riberiegos, A.H.N., Consejos, leg. 7133 